\title{
Baena Zapatero, Alberto; Roselló Soberón, Estela (Coord.) Mujeres en la Nueva España
}

Eduardo Torres Alonso*

México: Universidad Nacional Autónoma de México, Instituto de Investigaciones Históricas, 2016. 280p.

El libro Mujeres en la Nueva España, coordinado por Alberto Baena Zapatero y Estela Roselló Soberón, forma parte de la prestigiada serie "Historia Novohispana” del Instituto de Investigaciones Históricas de la Universidad Nacional Autónoma de México y es producto de coloquio internacional, celebrado en dicha institución, con el mismo título, en octubre de 2012. Los participantes en el acto académico, ahora coautores del libro, dispusieron de tiempo para transformar sus presentaciones orales en textos escritos formales, actualizados y corregidos. El índice de la obra advierte al lector que se analizarán una variedad de temas: la construcción historiográfica de las mujeres en la segunda mitad del siglo XX; los conventos femeninos y el monacato novohispano; la joyería femenina y la estética de los adornos; las mujeres fandangueras; en fin, el castigo judicial de los pecados públicos.

La introducción corre a cargo de Pilar Pérez Cantó, misma que no sólo consiste en un discurso sobre los trabajos reunidos, sino que ofrece una reflexión sobre la condición, papel y circunstancias de las mujeres a lo largo del tiempo en América Latina, y sobre las teorías que han moldeado los comportamientos entre los géneros.

El primer capítulo, escrito por Isabel Morant, se titula "Mujeres e historia. La construcción de una historiografía 1968-2010”, cuyo contenido ofrece una periodización de la etapas por las que a atravesado la historia de las mujeres, rescatando los más significativos debates, problemas epistemológicos y autoras.

\footnotetext{
* Universidad Nacional Autónoma de México (UNAM), Facultad de Ciencias Políticas y Sociales. Ciudad Universitaria, Delegación Coyoacán, D.F., México. etorres.alonso@gmail.com
} 
El análisis de las mujeres privilegiadas en el Valle de Orizaba, con el recurso a la microhistoria, es lo que se presenta en el segundo capítulo, "El Condado del Valle de Orizaba a través de sus mujeres", de Javier Sanchiz. El tratamiento investigativo a las mujeres con títulos nobiliarios, titulares o consortes, tiene que hacerse, muchas veces, con relación a su esposo ya que, con base en la documentación, su papel era de gestoras de la "casa nobiliaria", haciendo a un lado su protagonismo, quedando, en consecuencia, bajo la sombra masculina. De esta manera, el papel hombre-esposo era determinante y predominante en el destino de las condesas y, podríamos decir, de las mujeres novohispanas.

"Hermanas en Cristo. Balances, aproximaciones y problemáticas del monacato novohispano" es el capítulo que sigue, el tercero, en el que su autora, Rosalva Loreto López, analiza los conventos de mujeres, en particular de los franciscanos, cuyo legado cultural es profundo en la Nueva España (fansciscanismo femenino cultural), su implantación y expansión, así como los éxitos de la rama femenina de los mendicantes; asimismo, se señalan las diferencias entre las hermanas de la orden.

Por su parte, Antonio Rubial García examina en el capítulo cuatro, "Las beatas, la vocación de comunicar", con base en las fuentes de la Inquisición y la hagiografía, a las mujeres que formaban parte del espacio beateril: aquellas que no estaban casadas y no eran profesas recluidas en un monasterio o beaterio, vestidas con atuendos particulares, y piadosas, situadas, no obstante, en los márgenes de alguna orden religiosa que les diera legitimidad.

"La joyería femenina novohispana. Continuidades y rupturas en la estética del adorno corporal" de Andreia Martins Torres, es el capítulo número cinco, en donde se señala que vida de la Nueva España, simbólicamente vista, fue organizada sobre la base de un complejo sistema social con personajes de tierras continentales diversas: indias, españolas, negras y chinas asimilaron los signos "externos dentro de los límites de su estructura mental" (Baena Zapatero; Roselló Soberón, 2016, p.172). Con todo, la singularidad de la joyería de la época radica en la "añadidura" o combinación que le dio la población heterogénea del territorio; es decir, la joyería europea o asiática que llegaba fue usada por grupos distintos con significados también diferentes.

El único capítulo escrito en coautoría es el sexto, "Surcando el lado oscuro de la luna. Mujeres fandangueras”, de Lizette Alegre González, Gonzalo Camacho Díaz, Lénica Reyes Zúñiga y José Miguel Hernández Jaramillo. En él, los autores rastrean las "huellas" de la mujer como símbolo de subversión, 
mediante el fandango - son de mujeres -, ya que ellas, las "fandangueras", usaban la fuerza simbólica de su cuerpo para exhibir a la sociedad que las negaba como personas, viéndolas, entonces, de forma exclusiva como cuerpos-símbolos.

El trabajo de Andrea Rodríguez Tapia, “'La Castrejón', una 'alcahueta’ o 'lenona' ante la justicia criminal en Nueva España, 1808-1812”, integra el séptimo capítulo, en el que se examina el proceso judicial contra María Manuela González Castrejón, formado por la Real Sala del Crimen por el delito de lenocinio, que había sido reconocido como tal desde Las Siete Partidas. Rodríguez Tapia señala que la actitud de las autoridades asentadas en sus territorios continentales de Occidente, a diferencia de aquellas en los ayuntamientos de Madrid y Sevilla, durante la Edad Moderna, era ambigua, ya que las mujeres que incurrían en la prostitución eran descalificadas, mientras que el hombre que se relacionaba con ellas no sufría sanción alguna. Manuela González fue sometida a proceso no por las prácticas que tenían lugar en su casa sino por el escándalo que denunciaron los vecinos. La sanción hacia ella fue más bien una advertencia para quienes ejercían la prostitución o "alcahueteaban" a las "mujeres públicas". En fin, conviene decir que los delitos sexuales, como el imputado a "La Castrejón" eran, hasta cierto punto, menores.

El penúltimo capítulo, el octavo, es responsabilidad de Estela Roselló Soberón y se titula "El mundo femenino de las curanderas novohispanas". Con un esbozo biográfico de María Calderón - curandera y mujer lejos de ser pasiva, encerrada y callada -, la autora centra su atención, precisamente, en las curanderas y en su actuar en las fronteras o márgenes de la sociedad como "negociadoras culturales", haciendo evidente los estereotipos que quienes practicaban ese oficio tenían sobre sí y el posterior reconocimiento, prestigio y fama de los que fueron merecedoras.

En fin, en el noveno capítulo, "Salir del silencio: lecturas y escritos femeninos en la prensa mexicana de principios del siglo XIX”, de Esperanza Mó Romero, se destaca la participación de las mujeres en las discusiones en la prensa, particularmente a través del Diario de México y se estudian el modelo de sociedad ilustrada al que se enfrentaron las mujeres decimonónicas y sus respuestas a dicho marco, enriqueciendo, con ello, el debate público. La presencia de algunas mujeres en los periódicos supuso un quiebre cualitativo significativo en la sociedad, ya que se proyectaba una "nueva imagen femenina, a la cual las lectoras podían conformarse, que desbordaba los límites del modelo 
tradicional que se divulgaba a través de [las] páginas" (Baena Zapatero; Roselló Soberón, 2016, p.273).

En suma, los trabajos contenidos en Mujeres en Nueva España exponen, con un lenguaje diáfano, las circunstancias, coyunturas y pormenores de las mujeres durante el siglo XIX, a excepción del texto de Isabel Morant, cuyo aporte teórico en torno a las etapas por las que ha pasado la historia de las mujeres, lo hace singular.

\section{REFERÊNCIA}

BAENA ZAPATERO, Alberto; ROSELLÓ SOBERÓN, Estela (Coord.) Mujeres en la Nueva España. México: Universidad Autónoma de México, Instituto de Investigaciones Históricas, 2016.

Reseña recibida el 8 de mayo de 2017.

Aprobada el 18 de junio de 2017.

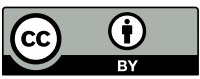

